\title{
Pre-fracture Mobility Using Standardized Scale as an Early Indicator of High Health Risk in Patients with a Hip Fracture
}

\author{
Keefai Yeong ${ }^{1} \cdot$ Radcliffe Lisk $^{1} \cdot$ Hazel Watters $^{2} \cdot$ Peter Enwere $^{3}$. \\ Jonathan Robin ${ }^{4}$. David Fluck ${ }^{5}$. Christopher H. Fry ${ }^{6} \cdot$ Thang S. Han $^{7,8}(-)$
}

Accepted: 22 October 2021 / Published online: 12 November 2021

(c) The Author(s) 2021

\begin{abstract}
Hip fracture in older adults is associated with poor prognosis. We tested the hypothesis that a single standardized measure, pre-fracture mobility, can be used as an early indicator of patients at high health risk after a hip fracture. Analysis of prospectively collected data of older adults admitted with a hip fracture between April-2009 and June-2019 in a single NHS hospital, UK. Pre-fracture mobility status (freely mobile, mobilising outdoors with one aid or with two aids, and limited to indoors), was used to predict length of stay (LOS) and mortality in hospital, and discharge destination. Among 3073 (2231 women, 842 men) admitted from their own home (mean \pm SD age $=82.7 \pm 9.3 \mathrm{yr}$ ), 159 died and 2914 survived to discharge: 1834 back to their home, 772 to rehabilitation, 66 to residential care, 141 to nursing care and 101 to unknown destinations. Compared with LOS of $15.9 \pm 15.6$ days in patients who mobilised freely before fracture (reference), those who were able to mobilise outdoors with one aid stayed 3.5 days, and those with two aids or confined to indoor mobility stayed one week longer in hospital. Inpatient mortality was increased among patients who mobilised outdoors with two aids: $\mathrm{OR}=2.1(95 \% \mathrm{CI}=1.3-3.3)$, and those limited to indoors: $\mathrm{OR}=2.1(1.3-1.5)$. Finally, a change in residence on discharge was more likely in those who mobilised outdoors with two aids $(\mathrm{OR}=1.8,95 \% \mathrm{CI}=1.2-2.6)$, and those limited to indoors $(\mathrm{OR}=1.9,95 \% \mathrm{CI}=1.2-2.9)$. In conclusion, pre-fracture mobility may be a useful early indicator for identifying patients at increased risk of adverse outcomes after an acute hip fracture.
\end{abstract}

Keywords Frailty $\cdot$ Geriatrics $\cdot$ Physical function $\cdot$ Healthcare

Thang S. Han

thang.han@rhul.ac.uk

Extended author information available on the last page of the article 


\section{Introduction}

Hip fractures have become more prevalent in adults as the population ages (McQueen \& Court-Brown, 2016; Veronese \& Maggi, 2018), with a large rise of incidence in both sexes after 70 years (Curtis EM et al., 2016). This life-changing event is associated with more adverse health outcomes and greater mortality (Bliuc et al., 2015; Papadimitriou et al., 2017; Sullivan et al., 2016), as well as personal and social costs (Veronese \& Maggi, 2018). The speed of functional recovery from a hip fracture is important both to patients and healthcare teams with regard to discharge planning and post-surgical care provision - either back to the patients' own home or a period of rehabilitation, or the need for a permanent change of residence to a higher level of residential or nursing care (Basu et al., 2016; Lisk et al., 2020a; Lisk et al., 2019). With a change of discharge destination, a number of arrangements is necessary involving hospital and community multidisciplinary teams, patients and their family, as well as the availability of residential/nursing care, which is a major determining factor for length of stay (LOS) in hospital (Fernandez \& Forder, 2008; Gaughan et al., 2015).

Most existing studies have focussed on investigations of clinical and socio-economic consequences of hip fracture (Peeters et al., 2016) and use pre-fracture function such as walking ability as a baseline measure for assessment of recovery (Tang et al., 2017). However, little is known about the impact of a patient's functional status pre-hip fracture which may have a bearing on the consequences of such a fracture. Because the majority of older adults who present with a hip fracture have pre-existing morbidities and poor physical function, pre-fracture mobility may be useful as an early indicator to identify patients at high health risk after a hip fracture. This early indicator enables healthcare teams to make rapid decisions on suitable clinical management to help improve the rate of recovery and to minimise adverse outcomes, and also to direct appropriate resources to rehabilitation and level of care in hospital and the community. The present study examined the association of pre-fracture mobility status with clinical outcomes including LOS and mortality in hospital, and a change of discharge destination from patients' own home to where higher levels of care are needed such as rehabilitation and residential/nursing care.

\section{Methods}

\section{Study Design, Patients and Setting}

We conducted a cross-sectional study of 3762 consecutive older individuals admitted with hip fractures between April 2009 and June 2019 to a single NHS hospital serving a population of over 410,000 people.

\section{Data Collection}

Through our participation in the National Hip Fracture Database (RCP, 2016; Lisk et al., 2020b), data were prospectively collected by a Trauma Coordinator for every 
patient admitted with a hip fracture from time of admission to discharge. The data comprised clinical characteristics and care quality, LOS during admission, and discharge destination. Patients' pre-fracture mobility status, assessed by a standardized tool (NHFD, 2013), was routinely collected. Pre-existing co-morbidities were identified from electronic record databases by disease codes categorised by the International Classification of Diseases (WHO, 2004). All data were updated regularly into a database managed by the lead orthogeriatrician. Demographic factors were documented including: residency prior to admission; medications; as well as dates of admission, surgery, and death or discharge. Nutritional status (risk of malnutrition, malnourished or well-nourished) was assessed using the Malnutrition Universal Screening Tool (MUST) protocol (Kondrup et al., 2002). Information on the type of fracture and on sedation was recorded including: general anaesthesia (GA) only; GA with fascia-iliaca block; spinal block; spinal block with fascia-iliaca block; or GA with spinal block.

\section{Categorisation of Variables}

Pre-fracture mobility status was categorised into five groups: 1) freely mobile without aids, 2) mobile outdoors with one aid, 3) mobile outdoors with two aids or frame, 4) some indoor mobility but never goes outside without help, and 5) no functional mobility (using lower limbs) (NHFD, 2013). Due to small numbers, the last two groups were merged together as a "limited to indoors" category for analysis in the present study. A change in discharge destination was defined as those who were admitted from their own home, but did not return home directly after discharge and transferred to places where increased care was provided, including rehabilitation units, residential home or nursing care. Those who died in hospital were excluded from this particular analysis.

Polypharmacy was defined as four or more different types of medications taken daily. The anticholinergic burden (ACB) scale was calculated from scores based on the list of medications developed by the Aging Brain Program (www.Agingbrain care). Type of sedation was categorised into: 1) GA with any other type of sedation or, 2) spinal nerve block with any other type of sedation except GA.

\section{Statistical Analysis}

To minimise bias introduced by patients admitted from nursing care and residential care who have poor mobility and prognosis, and to allow analysis of change in discharge destination to higher levels of residential care, only those who were admitted from their own home were selected for analysis in the present study. Group data are given as mean values $\pm \mathrm{SD}$, or median and interquartile range where data were not normally distributedsuch as LOS. Differences in LOS between groups of pre-fracture mobility were tested by Kruskal-Wallis tests. Differences between categorical outcome variables were assessed by $\chi^{2}$-squared tests, or by Fisher's exact tests when the expected counts were less than 5. Logistic regression was conducted to assess the association of pre-fracture mobility status with outcome measures including death in hospital, as well as change in residence 
on discharge. The results are presented in four models; model 1 - unadjusted; model 2 -adjusted for age and sex, model 3 - additional adjustment for years of study to model 2, and model 4-additional adjustment for LOS to model 3. Results were expressed as odds ratios (OR) and 95\% confidence intervals (CI). Analysis on a subsample of 440 patients was performed to examine the relationship between pre-fracture mobility and co-existing morbidities and polypharmacy. Analyses were performed using IBM SPSS Statistics, v25.0 (IBM Corp., Armonk, NY).

\section{Results}

From a total of 3762 patients admitted, 376 (9.3\%) came from residential care, 253 (6.2\%) from nursing care and $3133(77.2 \%)$ from their own home. Among patients admitted from their own home, 3073 had information on pre-fracture and these were selected for analysis. There were 2231 (72.6\%) women and $842(27.4 \%)$ men with mean age $82.7 \pm 9.3$ years, 159 died in hospital and 2914 survived for discharge: 1834 back to their home, 772 to rehabilitation, 66 to residential care, 141 to nursing care and 101 to unknown destination (Fig. 1). The mean LOS during admission was $18.4 \pm 17.0$ days.

There were slightly more left $(52.7 \%)$ and right (47.3\%) hip fractures: $17.4 \%$ had intertrochanteric, $78.2 \%$ intracapsular, and $4.4 \%$ subtrochanteric fractures. Almost all patients received physiotherapist assessment. The majority of patients

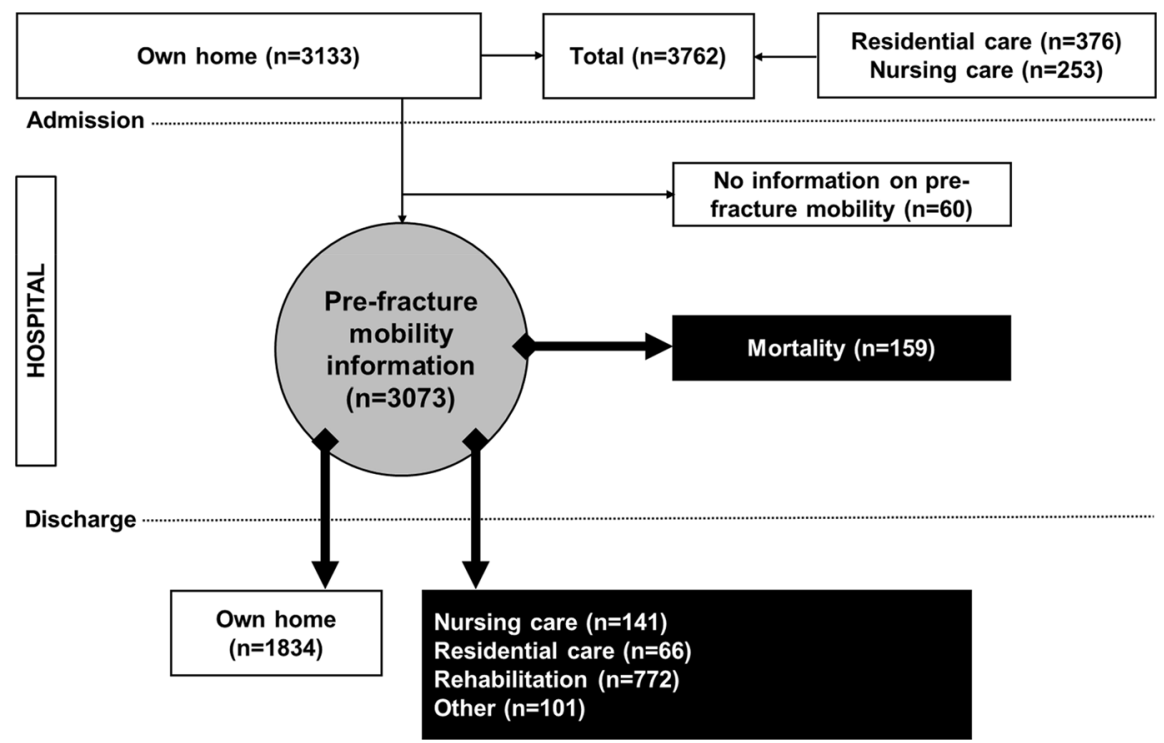

Fig. 1 Flowchart showing distribution of patients from the time of admission for a hip fracture to discharge 
$(87.2 \%)$ received GA for sedation during their hip surgery and the remaining $12.8 \%$ had nerve block without GA.

Overall, adverse outcomes were lowest among those who could mobilise freely before their hip fractures. The proportions of patients who did not return to their own home on discharge, discharged to rehabilitation and residential care increased with poorer pre-fracture mobility, while the proportions for those who were discharged to nursing care peaked among those who could mobilise with two aids (Table 1). A similar progressive increase in the proportions of patients who died in hospital was associated with worsening pre-fracture mobility $\left(\chi^{2}=22.7, P<0.001\right.$, Fig. 2$)$.

Compared with patients who were able to mobilise freely before hip fracture (the reference group), those with poorer pre-fracture mobility were significantly older (ANOVA: $F=96.8 ; P<0.001$ ). The mean age of the reference group was $80.0 \pm 9.5$ years, while that of those who mobilised outdoors with one aid was 5.3 years older $(95 \% \mathrm{CI}=4.5-6.1, P<0.001)$ and with two aids was 5.6 years older $(4.7-6.5, P<0.001)$ : those limited to indoors was 5.7 years older $(4.6-6.8$, $P<0.001)$.

The median (interquartile range) LOS for the entire group was 13.0 days (8.0-22.6), and significantly differed between pre-fracture mobility groups (Kruskal-Wallis test: $\chi^{2}=114, P<0.001$ ). The median (interquartile range) LOS for patients who were freely mobile was 11.2 days (7.1-19.1), rising to 14.1 days (8.8-23.0) for those mobilising outdoors with one aid, and to 16.1 days (9.6-28.6) for those mobilising outdoors with two aids or limited to indoors (Fig. 3A).

There were also significant differences in LOS between patients who were discharged to different destination of residence (Kruskal-Wallis test: $\chi^{2}=211$, $P<0.001$ ). The median (interquartile range) LOS for patients who were discharged back home was 13.0 days (7.8-22.9), for those who went to rehabilitation was 11.8 days (8.2-17.5), whilst the LOS for those who were transferred to residential care was 21.9 days (11.5-34.8), and to nursing care as new residents was 37.7 days (23.3-66.4) (Fig. 3B).

Compared to patients who mobilised freely, the age- and sex-adjusted risk of in-patient mortality was increased among patients who mobilised outdoors with two aids: $\mathrm{OR}=2.1,95 \% \mathrm{CI}=1.3-3.4$, and indoors: $\mathrm{OR}=2.1,1.3-3.5$. Finally, a change in residence on discharge was more likely in those who mobilised outdoors with two aids: $\mathrm{OR}=1.8,1.2-2.6$, and indoors: $\mathrm{OR}=1.9,1.2-2.9$. Additional adjustment for years of study and LOS in hospital did not change or minimally attenuated the association between pre-fracture mobility and outcomes (Table 2).

Finally, analysis of a subsample was conducted in 440 patients who had similar age $($ mean $=82.8 \pm 8.9$ years $)$ and sex distribution $(314(71.4 \%)$ women and $126(28.6 \%)$ men) to those of the entire sample. Poorer pre-fracture mobility was associated with several co-existing chronic conditions including dementia, Parkinson's disease, and stroke, as well as anticholinergic burden and polypharmacy and high 4AT, and risk of malnutrition (Table 3). 


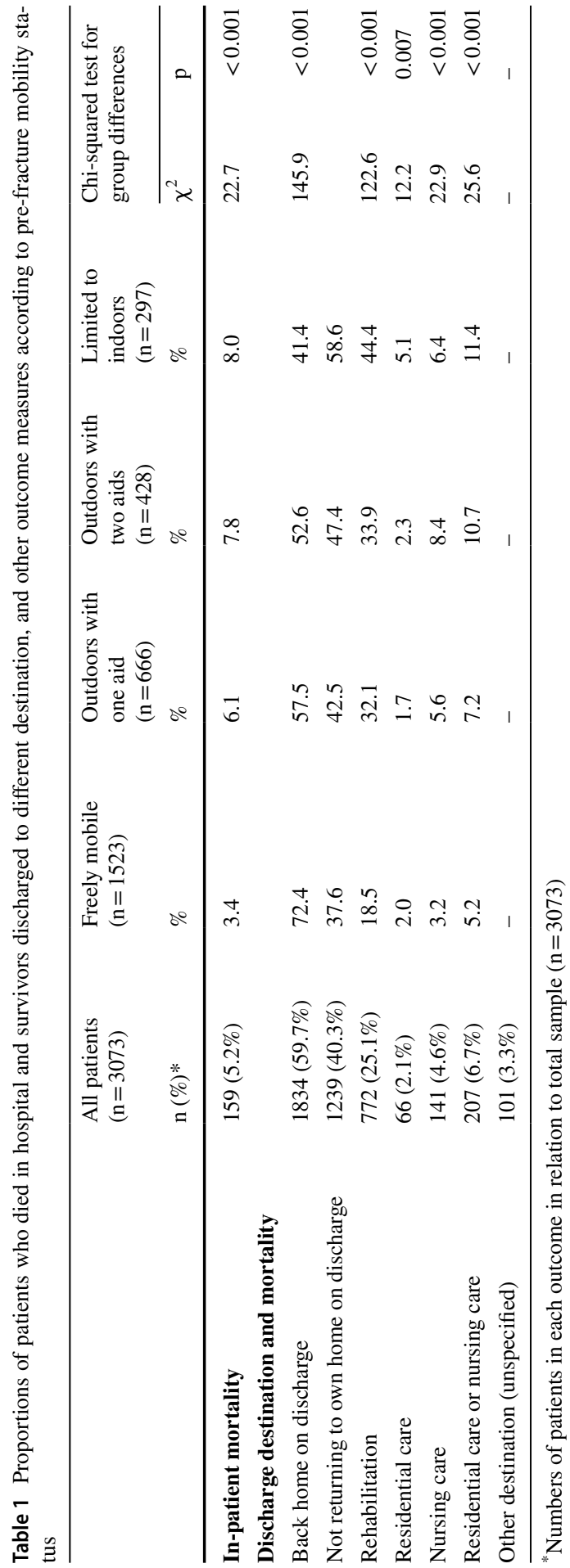


Fig. 2 Rates of mortality in relation to pre-fracture mobility status

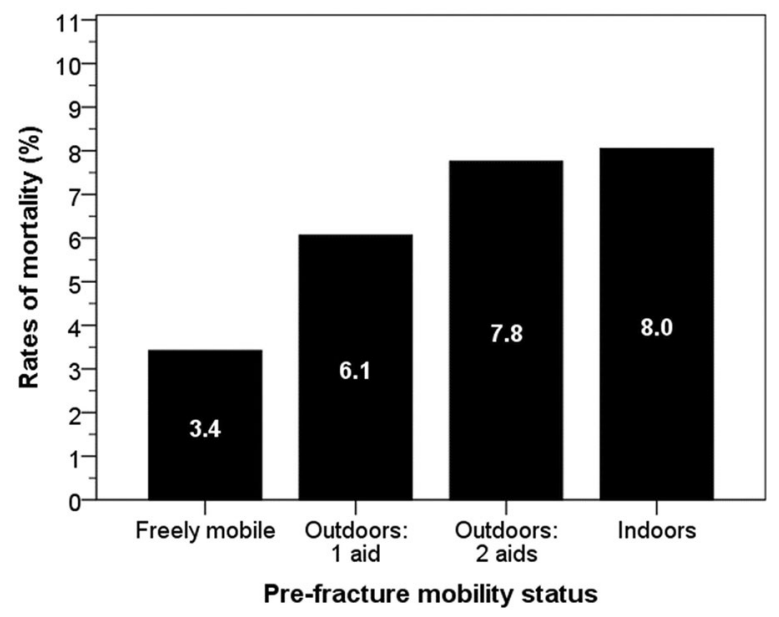

\section{Discussion}

Evidence from our study supports that a single measure of pre-fracture mobility may be served as an early indicator in the identification of patients with poorer health outcomes after a hip fracture. Compared with patients who could mobilise freely prior to hip fracture, patients whose mobility limited them to indoors, there was greater risks of mortality in hospital and being discharged to residential/nursing care. These increased risks were independent of age and sex. LOS was increased by a week among those who mobilised with two aids or limited to indoors.

Our findings are consistent with previous studies on pre-fracture mobility and health outcomes. Ingemarsson et al. (2003) found that patients who could walk outdoors unaided before a hip fracture were more likely to perform physical activity better a year after hip surgery, compared to those with more limited mobility. Another study found pre-facture mobility was the most significant predictor of being able to continue to live at home one year after discharge from a hip fracture surgery (Parker \& Palmer, 1995). Our observations in patients with hip fracture are similar to those in stroke patients. A study by Han et al. (2020) found that increased pre-stroke functional disability (assessed by modified Rankin Scale) was associated with post-stroke mortality, increased LOS in hospital and discharge to institutional care. Pre-fracture function such as mobility status assessed by standardized tool is therefore a useful early prognostic indicator of outcome measures for older patients who have suffered a hip fracture. The evidence of stepwise increments in adverse outcome measures with poorer pre-fracture mobility shown in the present study provides further information on allocation of healthcare provisions to those who are at greatest need, and also supports the need for preventative and early interventional measures.

The relationship between pre-fracture mobility status and health outcome measures is complex. Analysis of a subsample in the present study revealed that patients with poor pre-fracture mobility were more likely to have co-existing co-morbidities 


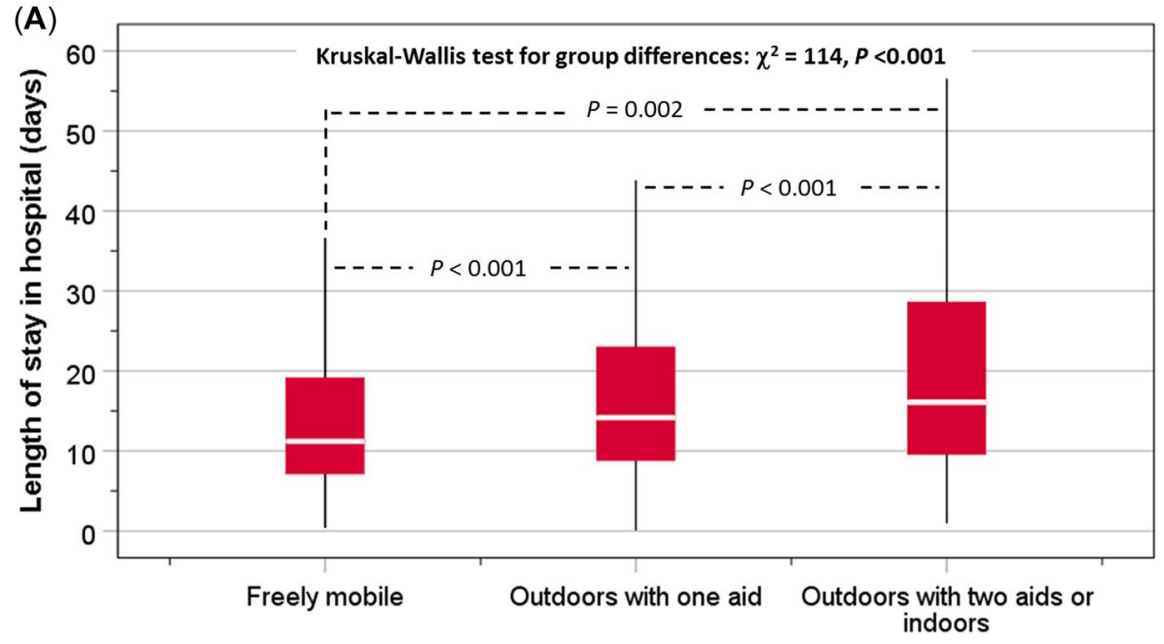

Pre-fracture mobility status

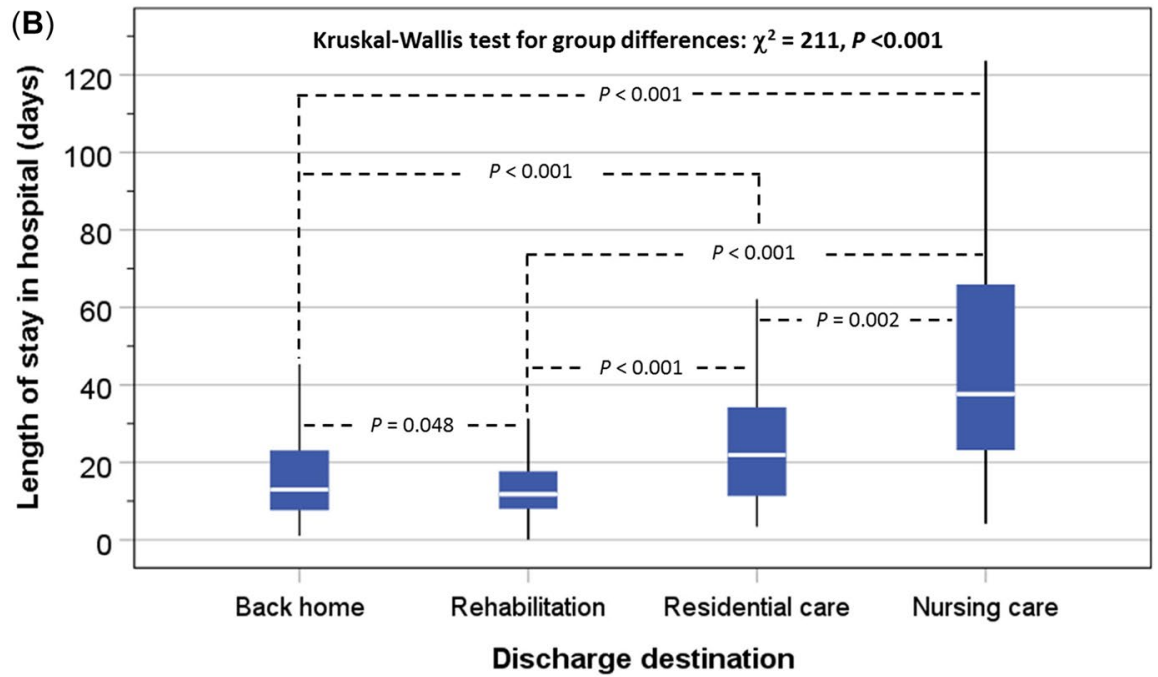

Fig. 3 Box plot representing median and interquartile ranges of length of stay in hospital according to pre-fracture status (A) and discharge destination (B); whiskers represent the 5th and 95th percentiles, and pairwise comparisons were assessed by Kruskal-Wallis test

that are particularly associated with poor physical function (dementia, Parkinson's disease and stroke). Analysis also showed that malnourishment/malnutrition and polypharmacy were more prevalent among patients with poorer mobility. Immobility and low body weight are known risk factors for bone loss (Evans, 2010a, 2010b; Pye et al., 2010), which is associated with increased risk of death (Pye et al., 2015). Moreover, acceleration of bone loss is an independent risk factor for post-fracture mortality (Bliuc et al., 2015). 
Table 2 Logistic regression unadjusted, adjusted for age, sex, years of study and length of stay in hospital

\section{Mobility status as risk factor for death and discharge destination: \\ Freely mobile group as reference}

\begin{tabular}{ll}
\hline Outdoors with one aid Outdoors with two Limited to indoors \\
aids
\end{tabular}
aids

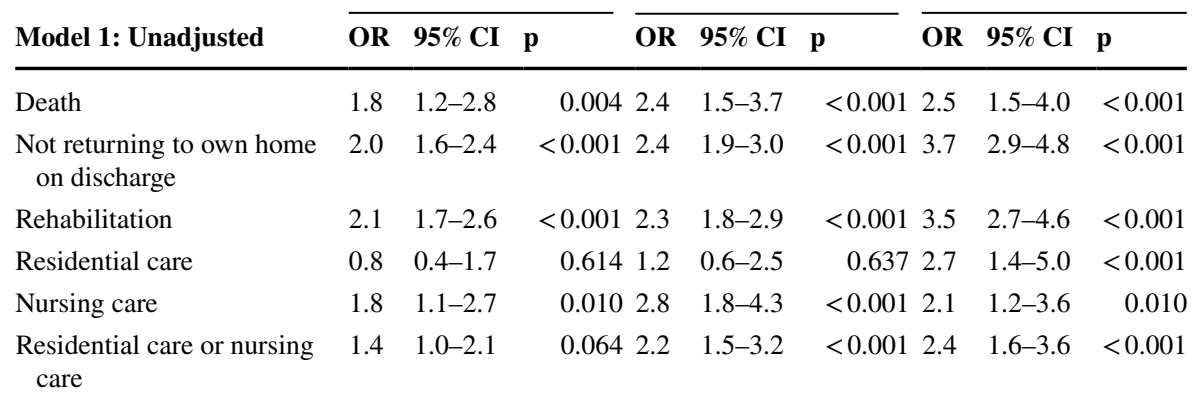

\section{Model 2: Adjusted for age} and sex

\begin{tabular}{|c|c|c|c|c|c|c|c|}
\hline Death & 1.5 & $1.0-2.3$ & 0.0542 .1 & $1.3-3.3$ & $0.001 \quad 2.1$ & $1.3-3.5$ & 0.003 \\
\hline $\begin{array}{l}\text { Not returning to own home } \\
\text { on discharge }\end{array}$ & 1.7 & $1.4-2.1$ & $<0.0012 .1$ & $1.7-2.6$ & $<0.0013 .2$ & $2.5-4.2$ & $<0.001$ \\
\hline Rehabilitation & 1.9 & $1.5-2.3$ & $<0.0012 .0$ & $1.6-2.6$ & $<0.0013 .1$ & $2.4-4.1$ & $<0.001$ \\
\hline Residential care & 0.7 & $0.3-1.4$ & 0.2680 .9 & $0.5-2.0$ & 0.8642 .1 & $1.1-3.9$ & 0.030 \\
\hline Nursing care & 1.5 & $1.0-2.3$ & 0.0872 .3 & $1.5-3.6$ & $<0.001 \quad 1.7$ & $1.0-2.9$ & 0.073 \\
\hline Residential care or nursing & 1.2 & $0.8-1.7$ & 0.4361 .8 & $1.2-2.6$ & 0.0041 .9 & $1.2-2.9$ & 0.004 \\
\hline
\end{tabular}
care

\section{Model 3: Model 2 plus year of study}

\begin{tabular}{|c|c|c|c|c|c|c|c|c|c|}
\hline Death & 1.5 & $1.0-2.4$ & 0.085 & 2.2 & $1.4-3.4$ & 0.001 & 2.2 & $1.3-3.8$ & 0.005 \\
\hline $\begin{array}{l}\text { Not returning to own home } \\
\text { on discharge }\end{array}$ & 1.7 & $1.4-2.0$ & $<0.001$ & 2.1 & $1.7-2.6$ & $<0.001$ & 2.8 & $2.1-3.7$ & $<0.001$ \\
\hline Rehabilitation & 1.8 & $1.5-2.3$ & $<0.001$ & 2.1 & $1.6-2.7$ & $<0.001$ & 2.4 & $1.8-3.2$ & $<0.001$ \\
\hline Residential care & 0.6 & $0.3-1.3$ & 0.213 & 0.8 & $0.4-1.8$ & 0.643 & 1.5 & $0.8-3.1$ & 0.214 \\
\hline Nursing care & 1.5 & $1.0-2.4$ & 0.062 & 2.3 & $1.5-3.6$ & $<0.001$ & 3.5 & $1.9-6.6$ & $<0.001$ \\
\hline $\begin{array}{l}\text { Residential care or nursing } \\
\text { care }\end{array}$ & 1.2 & $0.8-1.7$ & 0.429 & 1.7 & $1.1-2.5$ & 0.008 & 2.7 & $1.7-4.3$ & $<0.001$ \\
\hline \multicolumn{10}{|l|}{$\begin{array}{l}\text { Model 4: Model } 3 \text { plus } \\
\text { LOS in hospital }\end{array}$} \\
\hline Death & 1.5 & $1.0-2.4$ & 0.055 & 2.4 & $1.5-3.8$ & $<0.001$ & 2.4 & $1.4-4.2$ & 0.002 \\
\hline $\begin{array}{l}\text { Not returning to own home } \\
\text { on discharge }\end{array}$ & 1.7 & $1.4-2.1$ & $<0.001$ & 2.2 & $1.7-2.7$ & $<0.001$ & 2.9 & $2.2-3.8$ & $<0.001$ \\
\hline Rehabilitation & 2.0 & $1.6-2.5$ & $<0.001$ & 2.5 & $1.9-3.2$ & $<0.001$ & 2.9 & $2.2-3.9$ & $<0.001$ \\
\hline Residential care & 0.6 & $0.3-1.2$ & 0.122 & 0.7 & $0.3-1.5$ & 0.340 & 1.2 & $0.6-2.5$ & 0.563 \\
\hline Nursing care & 1.3 & $0.8-2.1$ & 0.259 & 1.7 & $1.1-2.7$ & 0.030 & 2.5 & $1.3-2.5$ & 0.004 \\
\hline $\begin{array}{l}\text { Residential care or nursing } \\
\text { care }\end{array}$ & 1.0 & $0.7-1.5$ & 0.992 & 1.3 & $0.9-1.9$ & 0.221 & 2.0 & $1.2-3.2$ & 0.005 \\
\hline
\end{tabular}

LOS length of stay 


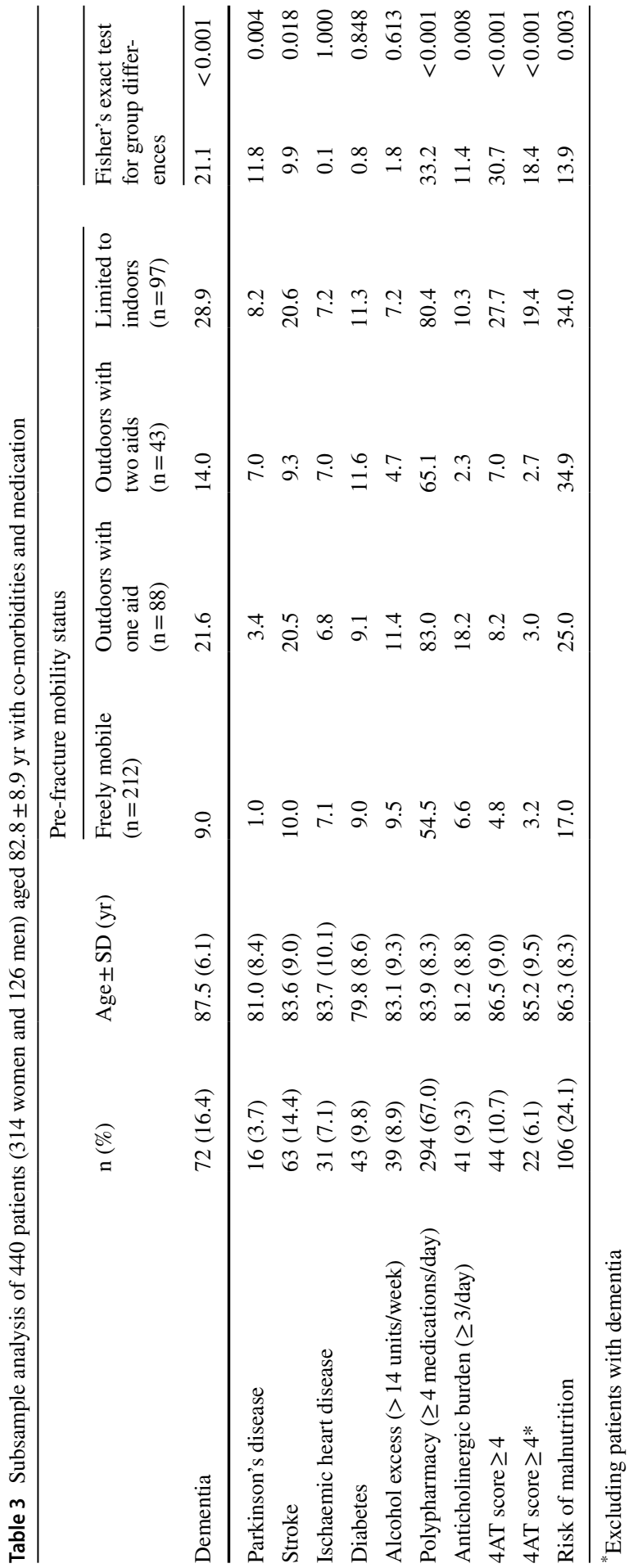


The association between increased LOS and several co-existing morbidities with worse pre-fracture mobility, as well as the association of increased LOS with a change to higher level of care on discharge, suggests that LOS is determined by a number of factors. These could include the underlying health of the patients, which could affect the speed of recovery from a hip fracture (Lisk et al., 2020a; Lisk et al., 2019), as well as the availability of residential/nursing care (Fernandez \& Forder, 2008; Gaughan et al., 2015); both of which would delay discharge. A recent study showed that compared with patients who stayed in hospital less than five days after a hip fracture repair, the risk of death 30 days after discharge was increased by $32 \%$ for those who stayed in hospital between 11 and 14 days and by $103 \%$ for those who stayed longer than 14 days (Nikkel et al., 2015).

There has been increasing interest in the use of pre-event indices such as the Nottingham Hip Fracture Score (NHFS) (Maxwell et al., 2008) and Rockwood Frailty Index (Rockwood et al., 2005) to predict outcomes in older adults. Some indices may contain a few and simple measures whilst others comprise multiple variables (Maxwell et al., 2008; Ravindrarajah et al., 2013; Rockwood et al., 2015). Pre-fracture mobility is easy to use in large sample sizes of older individuals, and thus is more practical than more complex indices. By contrast, the NHFS requires age, sex, admission haemoglobin, Abbreviated Mental Test Score, residence, co-morbidities, active malignancy within 20 years-these scores summate to a scale of 0 to 10 (Maxwell et al., 2008).

The NHFS was also examined in a subsample of this cohort and was shown to relate to a number of adverse outcomes (Lisk et al., 2020a, 2020b). It would be of interest to compare the performance of pre-fracture mobility and NHFS on outcomes in the future. A prospective study is suggested to increase the confidence of the ability of these indices to predict outcomes. Further study could be extended to older individual amongst the general population.

The strengths of this study include data from a large number of participants collected consecutively over a relatively long period of ten years, and measured by standardized protocols. Bias from individuals who were likely to have poorer health and thus mobility was minimised by excluding patients who were admitted from residential care and nursing care. This was confirmed by an analysis conducted prior to the decision was made: compared with selected patients who were admitted from own home, excluded patients who were admitted from residential care or nursing care were significantly $(P<0.001)$ older by 4.9 years and 4.7 years respectively, with higher proportions of pre-fracture mobility limited to indoors ( $11.2 \%$ vs $43.9 \%$ vs $48.0 \%)$ and mortality in hospital (6.4 vs $8.8 \%$ vs $8.2 \%$ ). Including those admitted from residential/nursing care exaggerated the association of pre-fracture mobility and outcomes. This technique of analysing only individuals living in their own home before hip fracture is commonly used for studies such as ours (Jalal et al., 1996; Nanjayan et al., 2014). It would be ideal to have complete data for every variable, but due to resource constraints, we only collected co-existing morbidities or medications for a subsample. However, this subsample was relatively large $(n=440)$ with similar characteristics to the entire study group. The present study did not attempt to adjust for co-morbidities because of the close association between pre-fracture and morbidity. Therefore 
having both of these measures in the same regression model would likely introduce a multicollinearity effect.

In conclusion, pre-fracture mobility, a simple and practical tool, is a useful early indicator for identifying patients at increased risk of adverse outcomes after an acute hip fracture.

Acknowledgements The authors wish to thank patients and all those who were involved in the project.

Author Contributions TSH reviewed the topic related literature and performed the study concept and analysis design. KY, RL and PE performed the study coordination and data collection. TSH wrote the first draft, analysed, interpreted the data and revised the manuscript. KY, RL, and CHF edited the manuscript. KY, RL, PE, DF, JR, MI-S, and CHF checked, interpreted results and commented on the manuscript. All authors approved the final version.

Funding None.

\section{Declarations}

Conflict of Interests The authors declare that they have no conflicts of interest.

Informed consent Informed consent was obtained from all individual participants included in the study.

Statement of Human and Animal Rights This article does not contain any studies with animals performed by any of the authors.

Ethical Approval This study does not require NHS Research Ethics Committee approval since it involves secondary analysis of anonymised data. This study was conducted in accordance with the 1964 Helsinki declaration and its later amendments or comparable ethical standards.

Open Access This article is licensed under a Creative Commons Attribution 4.0 International License, which permits use, sharing, adaptation, distribution and reproduction in any medium or format, as long as you give appropriate credit to the original author(s) and the source, provide a link to the Creative Commons licence, and indicate if changes were made. The images or other third party material in this article are included in the article's Creative Commons licence, unless indicated otherwise in a credit line to the material. If material is not included in the article's Creative Commons licence and your intended use is not permitted by statutory regulation or exceeds the permitted use, you will need to obtain permission directly from the copyright holder. To view a copy of this licence, visit http://creativecommons.org/ licenses/by/4.0/.

\section{References}

Aging Brain Program. www.agingbraincare.org/tools/abcanticholinergic-cognitive-burden-scale.

Bliuc, D., Alarkawi, D., Nguyen, T. V., Eisman, J. A., \& Center, J. R. (2015). Risk of subsequent fractures and mortality in elderly women and men with fragility fractures with and without osteoporotic bone density: The Dubbo Osteoporosis Epidemiology Study. Journal of Bone and Mineral Research, 30(4), 637-646. https://doi.org/10.1002/jbmr.2393

Basu, N., Natour, M., Mounasamy, V., \& Kates, S. L. (2016). Geriatric hip fracture management: Keys to providing a successful program. European Journal of Trauma and Emergency Surgery, 42(5), 565-569. https://doi.org/10.1007/s00068-016-0685-2

Curtis, E. M., van der Velde, R., Moon, R. J., van den Bergh, J. P., Geusens, P., de Vries, F., van Staa, T. P., Cooper, C., \& Harvey, N. C. (2016). Epidemiology of fractures in the United Kingdom 
1988-2012: Variation with age, sex, geography, ethnicity and socioeconomic status. Bone, 87, 19-26. https://doi.org/10.1016/j.bone.2016.03.006

Evans WJ. Skeletal muscle loss: cachexia, sarcopenia, and inactivity. (2010). The American Journal of Clinical Nutrition 91(4), 1123S-7S.

Evans, W. J. (2010b). Skeletal muscle loss: Cachexia, sarcopenia, and inactivity. The American Journal of Clinical Nutrition, 91(4), 1123S-1127S. https://doi.org/10.3945/ajcn.2010.28608a

Fernández, J. L., \& Forder, J. (2008). Consequences of local variations in social care on the performance of the acute health care sector. Applied Economics, 40(12), 1503-1518. https://doi.org/10.1080/ 00036840600843939

Gaughan, J. M., Gravelle, H. S., \& Siciliani, L. (2015). Testing the bed-blocking hypothesis: Does higher supply of nursing and care homes reduce delayed hospital discharges? Health Economics, 24(S1), 32-44.

Han, T. S., Fry, C. H., Gulli, G., Affley, B., Robin, J., Irvin-Sellers, M., Fluck, D., Kakar, P., Sharma, S., \& Sharma, P. (2020). Prestroke disability predicts adverse poststroke outcome: A registry-based prospective cohort study of acute stroke. Stroke, 51(2), 594-600. https://doi.org/10.1161/strokeaha. 119.027740

Ingemarsson, A. H., Frandin, K., Mellstrom, D., \& Möller, M. (2003). Walking ability and activity level after hip fracture in the elderly-a follow-up. Journal of Rehabilitation Medicine, 35(2), 76-83. https://doi.org/10.1080/16501970306113

Jaglal, S. B., Sherry, P. G., \& Schatzker, J. (1996). The impact and consequences of hip fracture in Ontario. Canadian Journal of Surgery, 39(2), 105-111.

Kondrup, J. E., Allison, S. P., Elia, M., Vellas, B., \& Plauth, M. (2003). ESPEN guidelines for nutrition screening 2002. Clinical Nutrition, 22(4), 415-421. https://doi.org/10.1016/s0261-5614(03)00098-0

Lisk, R., Uddin, M., Parbhoo, A., Yeong, K., Fluck, D., Sharma, P., Lean, M. E., \& Han, T. S. (2019). Predictive model of length of stay in hospital among older patients. Aging Clinical and Experimental Research, 31(7), 993-999. https://doi.org/10.1007/s40520-018-1033-7

Lisk, R., Yeong, K., Enwere, P., Jenkinson, J., Robin, J., Irvin-Sellers, M., Fluck, D., Osmani, A., Sharmin, R., Sharma, P., Fry, C. H., \& Han, T. S. (2020a). Associations of 4AT with mobility, length of stay and mortality in hospital and discharge destination among patients admitted with hip fractures. Age and Ageing, 49(3), 411-417. https://doi.org/10.1093/ageing/afz161

Lisk, R., Yeong, K., Fluck, D., Fry, C. H., \& Han, T. S. (2020b). The ability of the Nottingham Hip Fracture Score to predict mobility, length of stay and mortality in hospital, and discharge destination in patients admitted with a hip fracture. Calcified Tissue International, 107(4), 319-326. https://doi. org/10.1007/s00223-020-00722-2

McQueen, M. M. (2016). Global forum: Fractures in the elderly. JBJS, 98(9), e36. https://doi.org/10. 2106/jbjs. 15.00793

Maxwell, M., Moran, C. G., \& Moppett, I. K. (2008). Development and validation of a preoperative scoring system to predict 30 day mortality in patients undergoing hip fracture surgery. British Journal of Anaesthesia, 101(4), 511-517. https://doi.org/10.1093/bja/aen236

National Hip Fracture Database National report. (2013). Prepared on behalf of the Clinical Effectiveness and Evaluation Unit at the Royal College of Physicians. https://www.nhfd.co.uk/20/hipfractureR. nsf/0/CA920122A244F2ED802579C900553993/\$file/NHFD\%20Report\%202013.pdf(Accessed October, 2019)

Nikkel, L. E., Kates, S. L., Schreck, M., Maceroli, M., Mahmood, B., \& Elfar, J. C. (2015). Length of hospital stay after hip fracture and risk of early mortality after discharge in New York state: retrospective cohort study. Bmj, 351.https://doi.org/10.1136/bmj.h6246

Nanjayan, S. K., John, J., Swamy, G., Mitsiou, K., Tambe, A., \& Abuzakuk, T. (2014). Predictors of change in 'discharge destination' following treatment for fracture neck of femur. Injury, 45(7), 10801084. https://doi.org/10.1016/j.injury.2014.02.005

Papadimitriou, N., Tsilidis, K. K., Orfanos, P., Benetou, V., Ntzani, E. E., Soerjomataram, I., KünnNelen, A., Pettersson-Kymmer, U., Eriksson, S., Brenner, H., \& Trichopoulou, A. (2017). Burden of hip fracture using disability-adjusted life-years: A pooled analysis of prospective cohorts in the CHANCES consortium. The Lancet Public Health, 2(5), e239-e246. https://doi.org/10.1016/s24682667(17)30046-4

Parker, M. J., \& Palmer, C. R. (1995). Prediction of rehabilitation after hip fracture. Age and Ageing, 24(2), 96-98.

Pye, S. R., Devakumar, V., Boonen, S., Borghs, H., Vanderschueren, D., Adams, J. E., Ward, K.A., Bartfai, G., Casanueva, F.F., Finn, J.D., Forti, G., Giwercman, A., Han, T. S., Huhtaniemi, I. T., Kula, K., 
Lean, M. E., Pendleton, N., Punab, M., Silman, A. J., Wu, F. C., \& O’Neill, T. W., EMAS Study Group. (2010). Influence of lifestyle factors on quantitative heel ultrasound measurements in middle-aged and elderly men. Calcified Tissue International, 86(3), 211-219. https://doi.org/10.1007/ s00223-009-9330-y

Pye, S. R., Vanderschueren, D., Boonen, S., Gielen, E., Adams, J. E., Ward, K. A., Lee, D. M., Bartfai, G., Casanueva, F. F., Finn, J. D., Forti, G., Giwercman, A., Han, T. S., Huhtaniemi, I. T., Kula, K., Lean, M. E., Pendleton, N., Punab, M., Wu, F. C., \& O’Neill, T. W. (2015). Low heel ultrasound parameters predict mortality in men: Results from the European Male Ageing Study (EMAS). Age and Ageing, 44(5), 801-807. https://doi.org/10.1093/ageing/afv073

Peeters, C. M., Visser, E., Van de Ree, C. L., Gosens, T., Den Oudsten, B. L., \& De Vries, J. (2016). Quality of life after hip fracture in the elderly: A systematic literature review. Injury, 47(7), 13691382. https://doi.org/10.1016/j.injury.2016.04.018

Royal College of Physicians. National Hip Fracture Database annual report 2017. RCP, London (2016). http://www.nhfd.co.uk/. Accessed 1 February 2019.

Ravindrarajah, R., Lee, D. M., Pye, S. R., Gielen, E., Boonen, S., Vanderschueren, D., Pendleton, N., Finn, J.D., Tajar, A., O'Connell, M. D., and Rockwood, K., Bartfai, G., Casanueva, F. F., Forti, G., Giwercman, A., Han, T. S., Huhtaniemi I. T., Kula, K., Lean, M. E., Punab, M., Wu, F. C., \& O’Neill, T. W., European Male Aging Study Group. (2013). The ability of three different models of frailty to predict all-cause mortality: Results from the European Male Aging Study (EMAS). Archives of Gerontology and Geriatrics, 57(3), 360-368. https://doi.org/10.1016/j.archger.2013.06. 010

Rockwood, K., Song, X., MacKnight, C., Bergman, H., Hogan, D. B., McDowell, I., \& Mitnitski, A. (2005). A global clinical measure of fitness and frailty in elderly people. CMAJ, 173(5), 489-495. https://doi.org/10.1503/cmaj.050051

Rockwood, K., Theou, O., \& Mitnitski, A. (2015). What are frailty instruments for? Age and Ageing, 44(4), 545-547. https://doi.org/10.1093/ageing/afv043

Sullivan, K. J., Husak, L. E., Altebarmakian, M., \& Brox, W. T. (2016). Demographic factors in hip fracture incidence and mortality rates in California, 2000-2011. Journal of Orthopaedic Surgery and Research, 11(1), 1-10. https://doi.org/10.1186/s13018-015-0332-3

Tang, V. L., Sudore, R., Cenzer, I. S., Boscardin, W. J., Smith, A., Ritchie, C., Wallhagen, M., Finlayson, E., Petrillo, L., \& Covinsky, K. (2017). Rates of recovery to pre-fracture function in older persons with hip fracture: An observational study. Journal of General Internal Medicine, 32(2), 153-158. https://doi.org/10.1007/s11606-016-3848-2

Veronese, N., \& Maggi, S. (2018). Epidemiology and social costs of hip fracture. Injury, 49(8), 14581460. https://doi.org/10.1016/j.injury.2018.04.015

World Health Organization. (2004). ICD-10: International statistical classification of diseases and related health problems: Tenth revision. WHO.

Publisher's Note Springer Nature remains neutral with regard to jurisdictional claims in published maps and institutional affiliations.

Keefai Yeong is consultant orthogeriatrian at Ashford and St. Peter's NHS Foundation Trust.

Radcliffe Lisk is consultant orthogeriatrian at Ashford and St. Peter's NHS Foundation Trust.

Hazel Watters is orthopaedic trauma nurse at Ashford and St. Peter's NHS Foundation Trust.

Peter Enwere is consultant orthogeriatrian at Ashford and St. Peter's NHS Foundation Trust.

Jonathan Robin is consultant in acute medicine at Ashford and St. Peter's NHS Foundation Trust.

David Fluck is consultant cardiologist at Ashford and St. Peter's NHS Foundation Trust.

Christopher H Fry is professor in Pharmacology and Neuroscience at Bristol University. 
Thang S Han is consultant endocrinologist at Ashford and St. Peter's NHS Foundation Trust and senior lecturer at Royal Holloway University of London.

\section{Authors and Affiliations}

\section{Keefai Yeong ${ }^{1} \cdot$ Radcliffe Lisk $^{1} \cdot$ Hazel Watters $^{2} \cdot$ Peter Enwere $^{3}$.} Jonathan Robin ${ }^{4}$. David Fluck ${ }^{5}$ Christopher H. Fry ${ }^{6} \cdot$ Thang S. Han ${ }^{7,8}$

1 Department of Orthogeriatrics, Ashford and St. Peter's NHS Foundation Trust, Guildford Road, Surrey KT16 0PZ Chertsey, UK

2 Department of Orthopaedic Trauma, Ashford and St. Peter's NHS Foundation Trust, Guildford Road, Surrey KT16 0PZ Chertsey, UK

3 Dementia Service, Ashford and St. Peter's NHS Foundation Trust, Guildford Road, Surrey KT16 0PZ Chertsey, UK

4 Department of Acute Medicine, Ashford and St. Peter's NHS Foundation Trust, Guildford Road, Surrey KT16 0PZ Chertsey, UK

5 Department of Cardiology, Ashford and St. Peter's NHS Foundation Trust, Guildford Road, Surrey KT16 0PZ Chertsey, UK

6 School of Physiology, Pharmacology and Neuroscience, University of Bristol, Bristol BS8 1TD, UK

7 Department of Endocrinology, Ashford and St. Peter's NHS Foundation Trust, Guildford Road, Surrey KT16 0PZ Chertsey, UK

8 Institute of Cardiovascular Research, Royal Holloway, University of London, Egham TW20 0EX, Surrey, UK 